\title{
Toward the total synthesis of ritterazine $\mathrm{N}^{*}$
}

\author{
Douglass F. Taber ${ }^{\ddagger}$, Jean-Michel Joerger, and Karen V. Taluskie \\ Department of Chemistry and Biochemistry, University of Delaware, Newark, DE \\ 19716, USA
}

\begin{abstract}
Zr-mediated equilibrating cyclocarbonylation of a designed triene led with high diastereocontrol to the ABC 6-6-5 tricyclic core of ritterazine N. The 5-5 EF spiroketal side chain of ritterazine $\mathrm{N}$ was prepared by equilibrating cyclization of an acyclic keto diol. The two components were coupled, and the D ring was assembled by intramolecular aldol condensation.
\end{abstract}

Keywords: natural product synthesis; computational organometallic chemistry; spiroketal construction; ketone alkylation; chromatographic resolution.

\section{INTRODUCTION}

The ritterazines, represented by ritterazine $\mathrm{N} 1$ (Fig. 1), found [1] in small quantities in the lipophilic extract of the tunicate Ritterella tokioka, induce apoptosis in apoptosis-resistant malignant cells. With the closely related cephalostatins, which show the same activity, they form a unique class of trisdecacyclic molecules featuring a pyrazine as the core ring, steroid-related structures, and spiroketal edge-rings ( $\mathrm{E}$ and F). Partial syntheses from steroid precursors of several of the 6-6-6-5 cephalostatins and derivatives have been accomplished [2]. There has been no report of efforts other than our own [3] toward the 6-6-5-5 ritterazines.

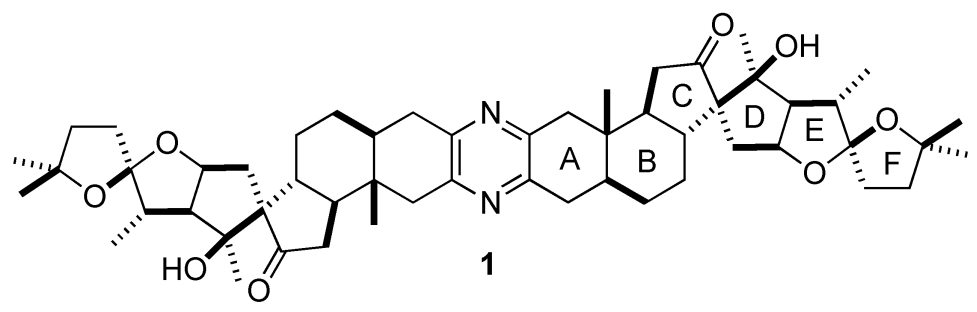

Fig. 1

To prepare ritterazine N 1, we planned (Scheme 1) to alkylate the ketone $\mathbf{2}$ with the triflate $\mathbf{3}$.

\footnotetext{
*Paper based on a presentation at the $14^{\text {th }}$ International Symposium on Organometallic Chemistry Directed Towards Organic Synthesis (OMCOS-14), 2-6 August 2007, Nara, Japan. Other presentations are published in this issue, pp. 807-1194.

¥Corresponding author: E-mail: taberdf@udel.edu
} 


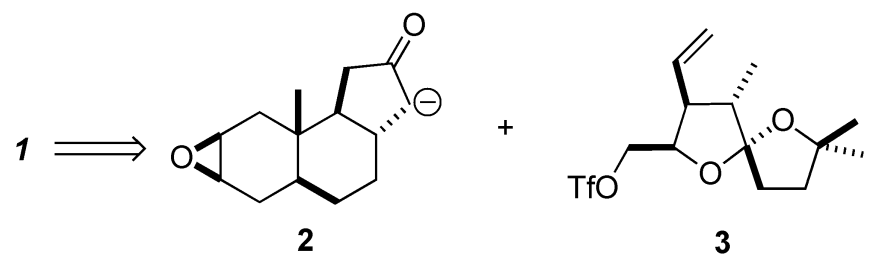

Scheme 1

\section{RESULTS AND DISCUSSION}

\section{Synthetic approach to the spiroketal 3}

We envisioned preparing 3 (Scheme 3 ) by the acid-catalyzed deprotection, cyclization, and equilibration of the ketone 4, to give 5a. Under acid-catalyzed conditions $6 / 5$ and 6/6 spiroketals generally equilibrate toward a particular diastereoisomer due to anomeric or substituent stabilization in the six-membered rings, but 5/5-spiroketals typically equilibrate to nearly a 1:1 mixture of epimers. An advantage in the synthesis of $\mathbf{5 a}$ is the presence of the methyl group adjacent to the spiro carbon, which we expected to exert significant stereocontrol. It was reasonable to expect that the methyl group on the E ring, which is cis to the vinyl group in $\mathbf{5 c}$ and $\mathbf{5 d}$, would equilibrate to the trans form. MOPAC PM3 calculations [4] with model compounds further encouraged us to adopt this route to $\mathbf{5 a}$ [3b].
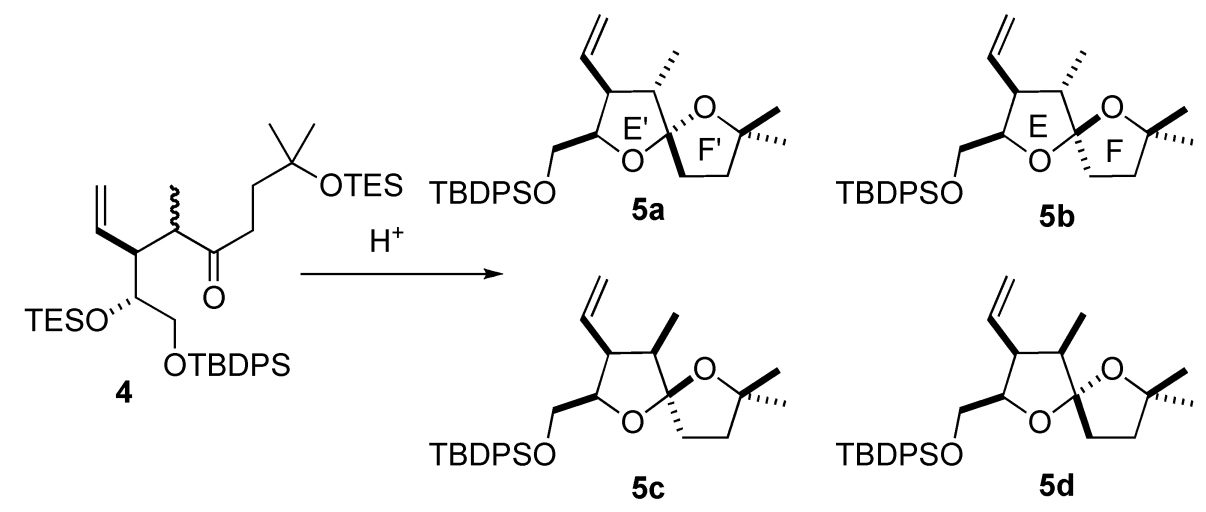

Scheme 2

\section{Preparation of the spiroketal 3}

The precursor 4 to the spiroketal 5 was prepared (Scheme 3) from the allylic alcohol 6 [5-8]. Sharpless epoxidation followed by oxidation to the aldehyde and methylenation gave the alkene 7 . Opening with the lithium salt of propionitrile provided $\mathbf{8}$ as the expected mixture of diastereomers. Attempted addition of nucleophiles converted $\mathbf{8}$ to the lactone, so the alcohol was protected as the TES ether before homologation to 4.

The crucial deprotection/cyclization of $\mathbf{4}$ was carried out with aqueous $\mathrm{HCl}$ in THF (Table 1, entry 1). The four diastereomers 5a-5d were separable by silica gel chromatography, and their structures could be assigned by NMR. The silyl ether $\mathbf{5 a}$ was also converted to a crystalline derivative, and its structure was secured by X-ray analysis. Further equilibration of the mixture of 5a-5d obtained in entry 1 was carried out with PPTS in $\mathrm{CH}_{2} \mathrm{Cl}_{2}$ (entry 2), which delivered 5a in $74 \%$ yield accompanied by $17 \%$ of a mixture of the other three diastereomers. The recovered mixture of ketals $\mathbf{5 b} \mathbf{b} \mathbf{5 d}$ could be subjected again to equilibration. For example (entry 3), under PPTS-catalyzed conditions a mixture of $\mathbf{5 c}$ and $\mathbf{5 d}$ was converted to $\mathbf{5 a}$ in $70 \%$ yield, based on starting material not recovered [9]. 


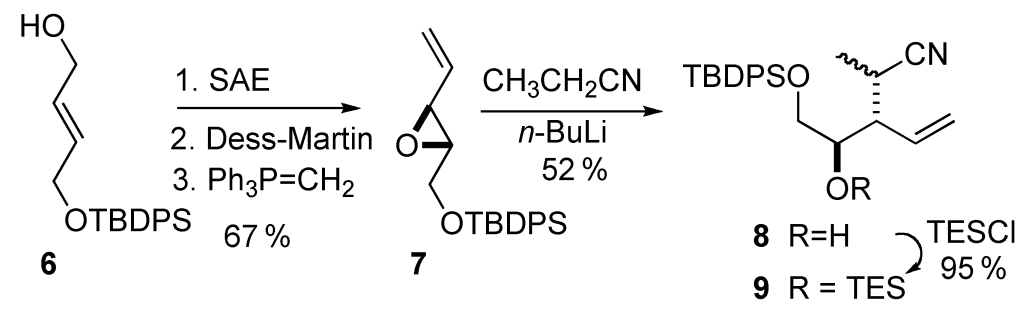

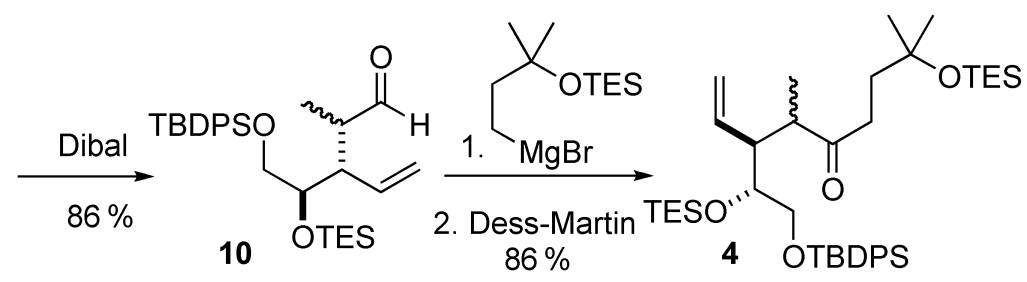
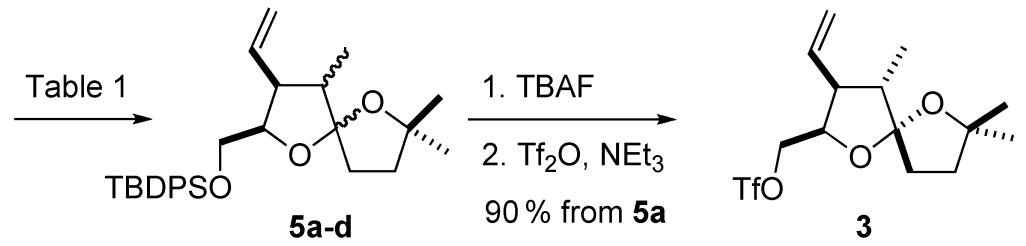

Scheme 3

Table 1 Equilibration of diastereomers 5a-d.

\begin{tabular}{|c|c|c|c|c|c|c|}
\hline \multirow{2}{*}{ Entry } & \multirow{2}{*}{ Starting material } & \multirow{2}{*}{ Conditions } & \multicolumn{4}{|c|}{ Yield } \\
\hline & & & $5 a$ & $5 b$ & $5 c$ & $5 d$ \\
\hline 1 & 4 & $A^{a}$ & $37 \%$ d & $3 \% d$ & $33 \% d$ & $15 \%$ d \\
\hline 2 & Product mixture of entry 1 & $\mathrm{~B}^{\mathrm{C}}$ & $74 \% b$ & \multicolumn{3}{|c|}{$17 \%^{b}$ of a mixture of $\mathbf{5 b}-\mathbf{d}$} \\
\hline 3 & $\mathbf{5 c}: \mathbf{5 d}=71: 29$ & B & $62 \%{ }^{b}$ & $3 \% d$ & $8 \% d$ & $3 \% d$ \\
\hline 4 & $5 a$ & $\mathrm{~B}$ & $81 \%{ }^{b}$ & $6 \% \mathrm{~b}$ & $3 \% b$ & $1 \%^{b}$ \\
\hline 5 & $5 c$ & $\mathrm{C}^{\mathrm{e}}$ & $0^{f}$ & $0^{f}$ & $54 \%^{f}$ & $46 \%{ }^{f}$ \\
\hline 6 & $5 d$ & C & $0^{f}$ & $0^{f}$ & $40 \%{ }^{f}$ & $60 \%{ }^{f}$ \\
\hline
\end{tabular}

aaq. $1 \mathrm{M} \mathrm{HCl} / \mathrm{THF}(1: 4), \mathrm{rt}, 3 \mathrm{~h}$.

bIsolated yield.

cPPTS (0.1 M), $\mathrm{CH}_{2} \mathrm{Cl}_{2}, 80{ }^{\circ} \mathrm{C}$ (sealed flask), 5-7 h.

${ }^{\mathrm{d}}$ Determined by NMR ratios from partially separated mixtures.

${ }^{\mathrm{e}} \mathrm{In} \mathrm{CDCl}_{3}$ for 4 weeks.

${ }^{\mathrm{N}} \mathrm{NMR}$ ratio.

(C) 2008 IUPAC, Pure and Applied Chemistry 80, 1141-1148 


\section{Preparation of the steroid core}

We have prepared 16 (Scheme 4) by cyclozirconation [10,11] of $\mathbf{1 4}$ followed by equilibration of the intermediate zirconacycles 15a-d to the thermodynamically more stable 15a, and trapping with carbon monoxide. The relative stability of the intermediate zirconacycles was predicted by ZINDO calculations [12].<smiles>C=CC=CC(=C)C1(C=C)CO1</smiles>

$60-70 \%$<smiles>C=CCCC1CC=CCC1(C)C=O</smiles>

13<smiles>COCCOC</smiles><smiles>c1ccccc1</smiles><smiles>C=CCCC1CC=CCC1(C)C=C</smiles>

14

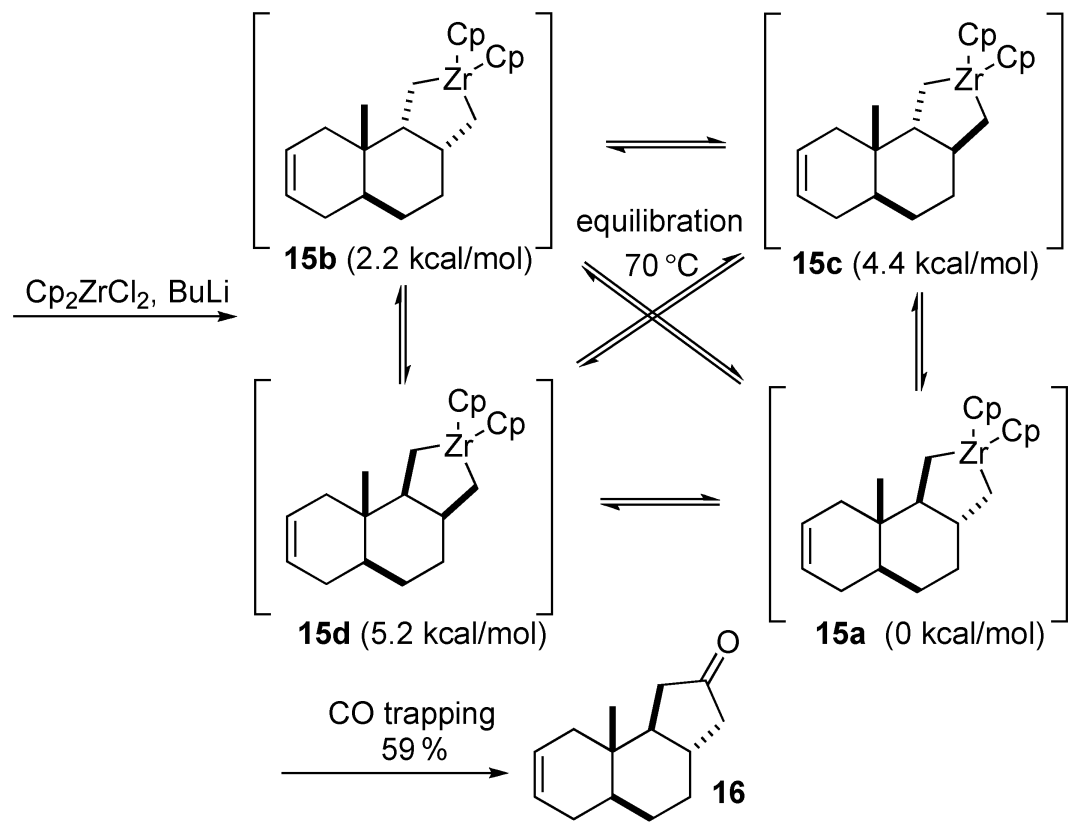

Scheme 4

\section{Assembly of the building blocks and dimerization}

The ketone 16 was racemic. To arrive at the enantiomerically pure epoxide $\mathbf{2}$, we exposed (Scheme 5) racemic 16 to mandelic acid and $N$-bromosuccinimide in the presence of 2,6-lutidine [13]. As expected, just two diastereomeric bromomandelates were formed, the product of $\mathrm{Br}(+)$ complexation to the more accessible face of the alkene followed by diaxial opening with mandelate anion. The diastereomeric mandelates were separated by column chromatography. The structures were assigned by ${ }^{1} \mathrm{H}$ NMR analysis, following our earlier precedent [13]. This assignment was confirmed by X-ray analysis of the mesylate 22 (Scheme 6). 


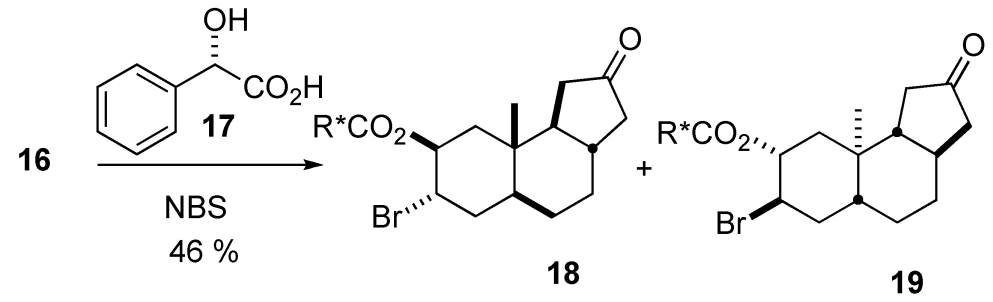

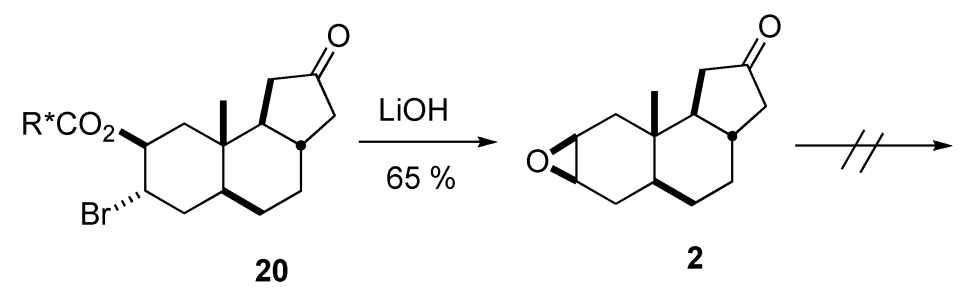<smiles>CCCC1Cc2nc3c(nc2CC1CC[C@H]1CC[C@@H]2CC(=O)C[C@H]2C1(C)C)CC1CC(=O)C[C@H]1C3</smiles>

Scheme 5

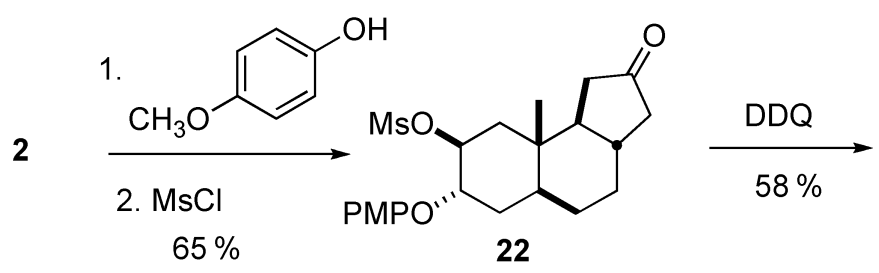<smiles>C=CC1C(CO[18O])O[C@]2(CC[C@@H](C)O2)[C@@H]1C</smiles>

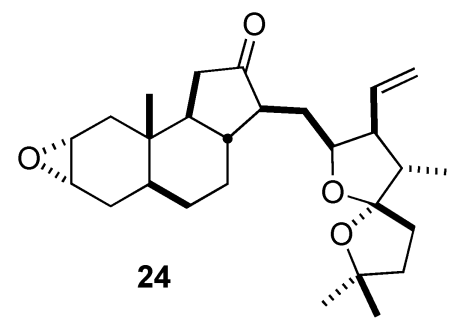

Scheme 6

(C) 2008 IUPAC, Pure and Applied Chemistry 80, 1141-1148 
Saponification of the bromomandelate 20 led directly to the "up" epoxide $\mathbf{2}$. We had previously shown that the analogous "down" epoxide, from direct epoxidation of 16, could be dimerized to 21 by opening with azide, oxidation to the ketone, and reduction with $\mathrm{Te} / \mathrm{NaBH}_{4}[14,15]$. To our surprise, only traces of $\mathbf{2 1}$ could be found when the same reductive protocol was applied to the azido ketone prepared from 2. It was clear that we would need to convert the "up" epoxide to the "down" epoxide before proceeding with the synthesis.

\section{Preparation and alkylation of the epoxy ketone}

The epoxide of $\mathbf{2}$ was inverted (Scheme 6) by opening with 4-methoxy phenol, followed by mesylation, to give 22. The mesylate $\mathbf{2 2}$ gave crystals that were suitable for X-ray analysis, confirming the previously assigned absolute configuration. Oxidative removal of the phenyl ether followed by cyclization then delivered the "down" epoxide 23.

The alkylation of $\mathbf{2 3}$ was challenging. We anticipated that we could arrive at $\mathbf{2 4}$ by kinetic deprotonation of the more accessible methylene of 23. In the event, the lithium enolate, prepared by exposing $\mathbf{2 3}$ to LDA, was not sufficiently reactive toward $\mathbf{3}$, even at room temperature and above. We eventually found that exposure of $\mathbf{2 3}$ to $\mathrm{KH}$, conveniently delivered as $\mathrm{KH}$ in paraffin [16], generated an enolate that reacted nearly quantitatively with the triflate $\mathbf{3}$.

Successfully reacting $\mathbf{2 3}$ with $\mathbf{3}$ was not the end of the difficulties. The product was a mixture both of regioisomeric C-alkylation products, and also of enol ethers from O-alkylation. It was necessary to develop conditions for acidic hydrolysis of the O-alkylated byproducts without upsetting the acid-sensitive spiroketal. We found success by stirring the crude alkylated mixture with $\mathrm{CDCl}_{3}$ (non-stabilized chloroform) containing a little bit of aqueous $\mathrm{HCl}$. The regenerated $\mathbf{2 3}$ could then be separated from the alkylated product $\mathbf{2 4}$ and from the alkylated regioisomer by column chromatography.

\section{The aldol condensation fails}

We had originally envisoned (Fig. 2) that the diketone $\mathbf{2 5}$ could cyclize to the aldol product $\mathbf{1}$. In the event, through a range of bases and solvents, we were not able to detect $\mathbf{1}$ in the crude reaction mix-

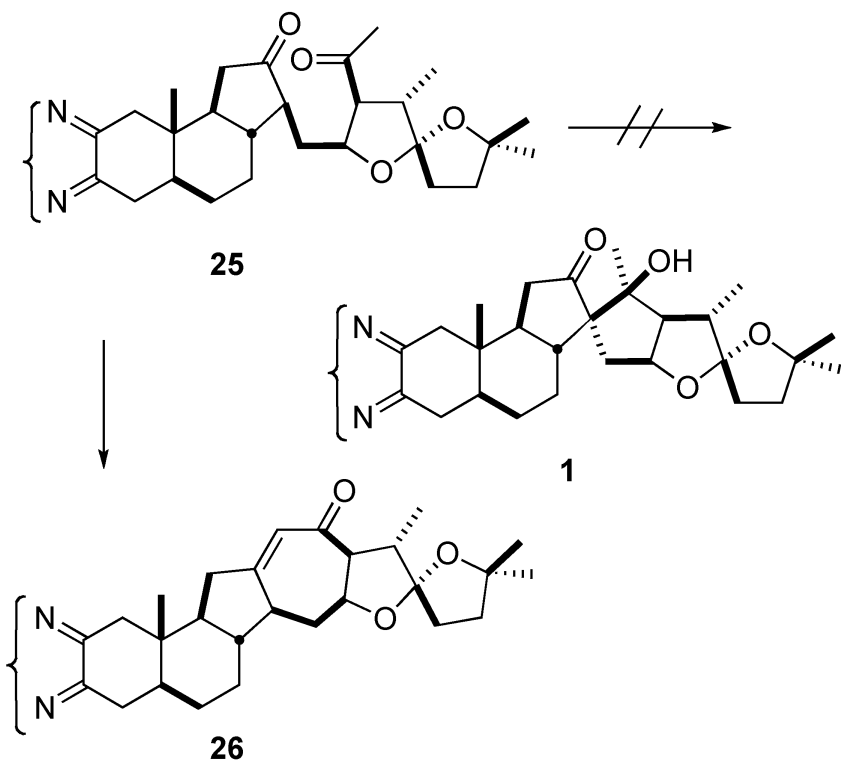

Fig. 2 
tures. Rather, the product appeared to be the cycloheptenone 26. We are investigating alternative strategies for the preparation of $\mathbf{1}$.

\section{Preparation of 18, 18'-desmethyl ritterazine N 29}

In the course of our investigations, we prepared (Scheme 7) the dimerized pyrazine 28. Diaxial opening of $\mathbf{2 4}$ with sodium azide delivered the alcohol $\mathbf{2 7}$. The ketone from the oxidation of $\mathbf{2 7}$ was not stable, so we submitted it directly to dimerization condiions, to give $\mathbf{2 8}$. We were pleased to observe that ozonolysis followed by brief exposure to base led to clean aldol condensation, to deliver 18 , 18 '-desmethyl ritterazine $\mathrm{N} \mathbf{2 9}$ as a single diastereomer.

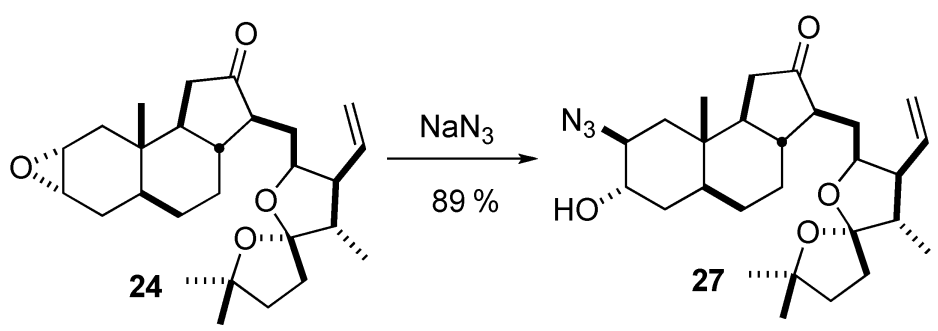

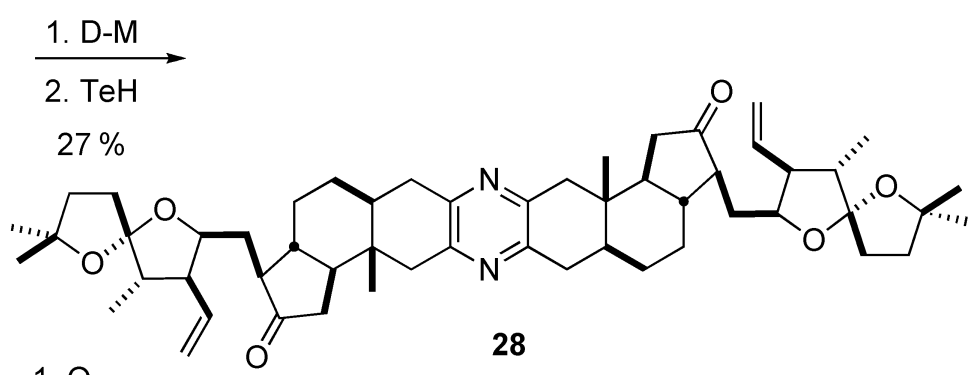

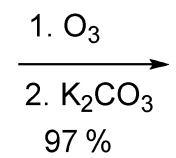

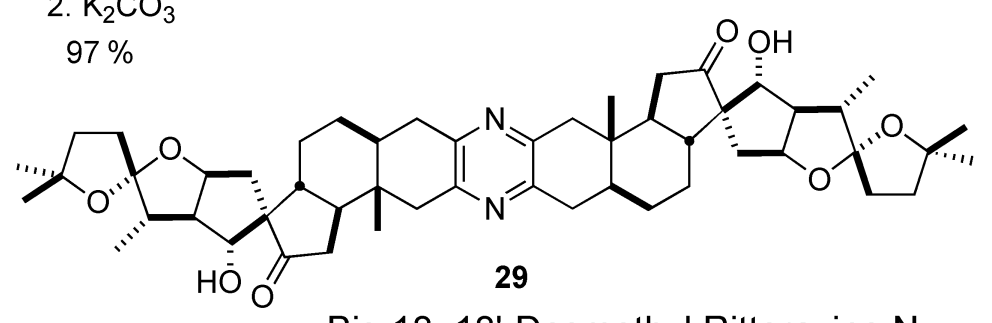

Bis-18, 18'-Desmethyl Ritterazine N

\section{Scheme 7}

\section{CONCLUSION}

We have prepared practical quantities of the enantiomerically pure ketones $\mathbf{2}$ and $\mathbf{2 3}$, and of the triflate $\mathbf{3}$, and we were able to alkylate the ketone $\mathbf{2 3}$ with the triflate $\mathbf{3}$. The capability to dispense scrupulously dry $\mathrm{KH}$ in paraffin in micromole quantities [16] was critical for the success of this alkylation. For the first time, this makes derivatives such as $\mathbf{2 9}$, having the full ring framework of the 6-6-5-5 ritterazines, available for further evaluation. 


\section{ACKNOWLEDGMENTS}

We thank John Dykins for recording mass spectra, Steve Bai for NMR assistance, Glenn Yap for X-ray structures, and the NIH (GM 60287) for financial support of this work.

\section{REFERENCES}

1. S. Fukuzawa, S. Matsunaga, N. Fusetani. J. Org. Chem. 62, 4484 (1997).

2. For leading references, see: (a) J. S. Lee, P. L. Fuchs J. Am. Chem. Soc. 127, 13122 (2005); (b) M. Nawasreh, E. Winterfeldt. Curr. Org. Chem. 7, 649 (2003).

3. For our published work toward the ritterazines, see: (a) D. F. Taber, K. V. Taluskie. J. Org. Chem. 71, 2797 (2006); (b) D. F. Taber, J.-M. Joerger. J. Org. Chem. 72, 3454 (2007).

4. For leading references to PM3, see: J. I. Seeman, J. B. Paine III, H. V. Secor, H. S. Im, E. R. Bernstein. J. Am. Chem. Soc. 114, 5269 (1992).

5. M. G. Organ, J. T. Cooper, L. R. Rogers, F. Soleymanzadeh, T. Paul. J. Org. Chem. 65, 7959 (2000).

6. Y. Mori, M. Asai, J.-i. Kawade, H. Furukawa. Tetrahedron 51, 5315 (1995).

7. W. R. Roush, J. A. Straub, M. S. VanNieuwenhze. J. Org. Chem. 56, 1638 (1991).

8. (a) M. Larchevêque, A. Debal. Synth. Commun. 10, 49 (1980); (b) S. K. Taylor, D. DeYoung, L. J. Simons, J. R. Vyvyan, M. A. Wemple, N. K. Wood. Synth. Commun. 28, 1691 (1998).

9. In parallel with our work, Shair reached the same conclusion about the relative configuration of the spiro center of the ritterazines: S. T. Phillips, M. D. Shair. J. Am. Chem. Soc. 129, 6589 (2007).

10. For the development of intramolecular diene cyclozirconation, including computational analysis, see: (a) W. A Nugent, D. F Taber. J. Am. Chem. Soc. 111, 6435 (1989); (b) D. F. Taber, J. P. Louey, Y. Wang, W. A. Nugent, D. A. Dixon, R. L. Harlow. J. Am. Chem. Soc. 116, 9457 (1994).

11. For the development of Zr-based intramolecular diene cyclocarbonylation, see: (a) E. Negishi, S. R. Miller. J. Org. Chem. 54, 6014 (1989); (b) D. F. Taber, Y. Wang. J. Am. Chem. Soc. 119, 22 (1997); (c) D. F. Taber, W. Zhang, C. L. Campbell, A. R. Rheingold, C. D. Incarvito. J. Am. Chem. Soc. 122, 4813 (2000).

12. For a leading reference to the use of ZINDO for transition-metal calculations, see: D. R. Kanis, M. A. Ratner, T. J. Marks, M. C. Zerner. Chem. Mater. 3, 19 (1991). Both ZINDO and MOPAC were used as implemented on a Tektronix CAChe workstation.

13. D. F. Taber, J. Liang. J. Org. Chem. 72, 4313 (2007).

14. (a) H. Suzuki, T. Kawaguchi, K. Takaoka. Bull. Chem. Soc. Jap. 59, 665 (1986); (b) J. U. Jeong, S. C. Sutton, S. Kim, P. L. Fuchs. J. Am. Chem. Soc. 117, 10157 (1995).

15. For an alternative route to pyrazines, see: D. F. Taber, P. W. DeMatteo, K. V. Taluskie. J. Org. Chem. 72, 1492 (2007).

16. For the advantages of KH in paraffin, see: D. F. Taber, C. G. Nelson. J. Org. Chem. 71, 8973 (2006). 